\title{
NEOLIBERALISMO EM QUESTÃO: INFLUÊNCIAS NO CAMPO EDUCACIONAL BRASILEIRO E NA PRODUÇÃO DO CONHECIMENTO
}

\author{
NEOLIBERALISM IN QUESTION: INFLUENCES IN THE BRAZILIAN \\ EDUCATIONAL FIELD AND IN THE PRODUCTION OF KNOWLEDGE
}

Nádia da Silva Tessaro

Mestre

Universidade Estadual de Maringá - UEM.

Maringá, Paraná - Brasil.

nahtessaro@gmail.com

Maria Luisa Furlan Costa

Doutora

Universidade Estadual de Maringá - UEM.

Maringá, Paraná - Brasil.

mlfcosta@uem.br

Vânia de Fátima Matias de Souza

Doutora

Universidade Estadual de Maringá - UEM. Maringá, Paraná - Brasil.

vfmsouza@uem.br

\begin{abstract}
Resumo: Este artigo objetiva discorrer sobre o percurso histórico da perspectiva econômica liberal e neoliberal, bem como sobre as possíveis influências na educação brasileira e a escassez da produção acadêmica nessa área. Tendo o materialismo histórico dialético como referencial adotado, o percurso metodológico utilizado foi: a) revisão sistemática de bases teóricas; b) busca de estudos publicados na base de dados "Scielo" entre 2007-2017, com os descritores: "trabalho docente", "precarização", "professor", "políticas educacionais" e "neoliberalismo". Foram encontrados 358 estudos, 157 relacionados ao "professor", $10 \mathrm{com}$ foco na "precarização", e 37 relacionados ao "neoliberalismo". Verificou-se que as pesquisas educacionais, que relacionam a perspectiva neoliberal com a educação, carecem de mais publicações, visto que os princípios neoliberais estão atrelados historicamente à formulação e execução de políticas públicas reformistas. Estas afetam o sistema educacional brasileiro, pois focalizam seus esforços na educação básica, em detrimento ao Ensino Superior, atendendo às demandas de mercado e acirrando ainda mais as desigualdades sociais.
\end{abstract}

Palavras-chave: Educação. Liberalismo. Neoliberalismo. Políticas educacionais.

\begin{abstract}
This article aims to discuss the historical course of the liberal and neoliberal economic perspective, as well as the possible influences on Brazilian education and the scarcity of academic production in this area. Having dialectical historical materialism as a reference, the methodological approach used was: a) systematic review of theoretical bases; b) search for studies published in the "Scielo" database between 2007-2017 with the descriptors "teacher work", "precarization", "teacher", "educational policies" and "neoliberalism". We found 358 studies, with "teacher" obtaining the largest amount of published research 157, "precarization" presented the lowest number 10, followed by the descriptor "neoliberalism" 37 . It was verified that the educational research that relates the neoliberal perspective to the education, need more publications, since the neoliberal principles are historically linked in the formulation and execution of reformist public policies that affect the Brazilian educational system, focusing its efforts in the basic education in detriment of Higher Education, meeting the demands of the market and further aggravating social inequalities.
\end{abstract}

Keywords: Education. Liberalism. Neoliberalism. Educational policies.

Para citar - (ABNT NBR 6023:2018)

TESSARO, Nádia da Silva; COSTA, Maria Luisa Furlan; SOUZA, Vânia de Fátima Matias de. Neoliberalismo em questão: influências no campo educacional brasileiro e na produção do conhecimento. Eccos - Revista Científica, São Paulo, n. 56, p 1-15, e10727, jan./mar. 2021. Disponível em: https://doi.org/10.5585/eccos.n56.10727. 


\section{Introdução}

A história da humanidade foi construída ao longo dos séculos por meio da ação dos próprios homens, que se propuseram a construir e a reconstruir saberes almejando o desenvolvimento da vida humana. Em diferentes períodos históricos, houve o desenvolvendo de um modelo distinto de homem e sociedade, que imprimiu novas formas de organização social, atreladas ao campo político e econômico. O homem de hoje, inserido no chamado sistema capitalista, é um homem que vende e compra força de trabalho. Neste contexto, a economia é tida como sinônimo de poder, capaz de promover uma hegemonia política.

Logo, trazer à cena o estado da arte da produção do conhecimento acerca da temática tratada, torna-se uma ação relevante para a área, uma vez que segundo Mendonça (2016) as pesquisas relacionados à busca do estado da arte são aquelas que se caracterizam por um levantamento bibliográfico, em que toda produção acadêmica é analisada sistemática e criticamente. Enfatiza-se, ainda, o fato de que esse tipo de estudo se destaca por possibilitar ao pesquisador um panorama das produções da área, bem como a evolução, características e possíveis falhas ou campos ainda pouco pesquisados.

Romanowski e Ens (2006, p.41) contribuem com essa discussão ao afirmarem que "um estado da arte pode constituir-se em levantamentos do que se conhece sobre determinada área, desenvolvimento de protótipos de análises de pesquisas, avaliação da situação da produção do conhecimento da área focalizada", a fim de "verificar, na multiplicidade e pluralidade de enfoques e perspectivas, indicativos para esclarecer e resolver as problemáticas históricas". No entanto, Mendonça (2016) em sua análise ressalta que o desenvolvimento de pesquisas do tipo Estado da Arte não devem ter um fim, tendo em vista os seus objetivos e a sua metodologia.

Nesta perspectiva, este estudo fará uma análise sistemática nos dados, ou seja, os dados serão trabalhados tendo como ponto central o entendimento de que "a análise ou revisão sistemática é um tipo de investigação científica que tem por objetivo reunir, avaliar criticamente e conduzir uma síntese dos resultados de múltiplos estudos primários. Ela também objetiva responder a uma pergunta claramente formulada, utilizando métodos sistemáticos e explícitos para identificar, selecionar e avaliar as pesquisas relevantes, coletar e analisar dados de estudos incluídos na revisão" (CORDEIRO et al, 2007, p.429). Assim, a investigação partiu do questionamento acerca de como se encontra o estado da arte da produção no Brasil, focalizada nos modos econômicos de organização conhecidos como 
liberais e neoliberais, apresentando seus princípios e sua inserção na América Latina, especialmente no Brasil, que possibilita verificar as possíveis aproximações com as políticas públicas educacionais aqui implementadas. Em um segundo momento, demonstraremos o panorama da produção do conhecimento educacional entre os anos de 2007-2017, por meio da busca na base de dados Scielo para, a partir dos descritores "trabalho docente", "precarização", "professor", "políticas educacionais" e "neoliberalismo", verificar quais as temáticas mais abordadas no decorrer de onze anos, bem como, revelar a quantidade de estudos que relacionam o neoliberalismo com a precarização da educação brasileira. A partir destes elementos centrais de busca, os dados foram organizados e categorizados por similaridades temáticas, abordadas na produção encontrada no referido período.

Esta discussão se faz pertinente, uma vez que, de acordo com Bourdieu (1998), a precariedade está alocada em todos os setores da sociedade, não se restringindo apenas ao setor da educação, pois o que se impera nas relações de produção são formas de inserção temporárias e interinas, típicas do modelo de acumulação flexível, que de acordo com Antunes (2006) têm-se intensificado a partir dos anos 1990, quando o Brasil foi marcado por um intenso processo de reestruturação produtiva do capital, o qual seguiu a mesma dinâmica dos países centrais. Oliveira (2004), contribuindo com essa discussão, aponta que a década de 1990 foi marcada por um novo processo a respeito das demandas educativas, e que foi um período no qual se observam as políticas educacionais passando a demarcar uma nova realidade, o chamado "imperativo da globalização".

\section{Liberalismo e neoliberalismo: passado e presente}

Acredita-se que o chamado liberalismo clássico date entre os séculos XVIII e XIX, tendo suas raízes fixadas a partir da publicação da obra de Adam Smith (1723-1790), intitulada de A Riqueza das Nações, no ano de 1776 (MORAES, 1997). Esta obra expõe um sistema de ideias que direcionam os princípios econômico-políticos, os quais a sociedade deveria estabelecer, para a obtenção do progresso das nações. Smith pregava que 
o mundo seria melhor - mais justo, racional, eficiente e produtivo - se houvesse a mais livre iniciativa, se as atitudes econômicas dos indivíduos e suas relações não fossem limitadas por regulamentos e monopólios garantidos pelo Estado ou pelas corporações de ofício. Prega a necessidade de desregulamentar e privatizar as atividades econômicas, reduzindo o Estado a funções definidas, que delimitassem apenas parâmetros bastante gerais para as atividades livres dos agentes econômicos. São três as funções do governo na argumentação de Smith: a manutenção da segurança interna e externa, a garantia da propriedade e dos contratos e a responsabilidade por serviços essenciais de utilidade pública (MORAES, 2001, p.5, grifo nosso).

O excerto supracitado expõe alguns princípios do pensamento liberal proposto por Smith, em que é possível notar a defesa pela "livre iniciativa" que seria impulsionada por meio da desregulamentação e privatização das atividades econômicas, enquanto que ao Estado caberia apenas gerir os assuntos estritamente gerais, deixando que o mercado por si mesmo se regulasse, o que ficou representado na expressão tradicionalmente conhecida como "a mão invisível” do mercado. Observe como Smith explica o sentido desta expressão:

uma vez eliminados inteiramente todos os sistemas, sejam eles preferenciais ou de restrições, impõe-se por si mesmo o sistema óbvio e simples da liberdade natural. Deixa-se a cada qual, enquanto não violar as leis da justiça, perfeita liberdade de ir em busca de seu próprio interesse, a seu próprio modo, e fazer com que tanto seu trabalho como seu capital concorram com os de qualquer outra pessoa ou categoria de pessoas. (SMITH, 1983, p.147).

Smith considerava que os indivíduos deveriam ter liberdade para buscar oportunidades de crescimento econômico, ou seja, por meio de seu próprio mérito, as pessoas poderiam concorrer umas com as outras, desde que a lei e a ordem fossem mantidas. Ele defendia a ordem natural, pois tinha a convicção de que

o esforço natural de cada indivíduo para melhorar a sua própria condição, quando se permite que ele atue com liberdade e segurança, constitui um princípio tão poderoso que, por si só, e sem qualquer outra ajuda, não somente é capaz de levar a sociedade à riqueza e à prosperidade, como também de superar uma centena de obstáculos impertinentes com os quais a insensatez das leis humanas com excessiva frequência obstrui o seu exercício (SMITH, 1983, p. 36).

Em suma, o liberalismo objetivava superar os "entraves" gerados pelo então mercantilismo (sistema econômico de trocas daquele período), bem como, o de suas instituições reguladoras, com o intuito de possibilitar a livre atuação do mercado econômico e, em contrapartida, conter "a viciosa mão visível do poder político". Para os liberais, o poder político que agia por meio dos "regulamentos estatais - mais especificamente, a política econômica dirigista do mercantilismo - e as corporações" impossibilitavam o progresso, sendo necessário limitar, então, as suas ações (MORAES, 2001, p. 7). 
Para Moraes (2001, p. 10), o liberalismo aproximou-se das correntes conservadoras durante o século XIX, defendendo a redução das ações do Estado (soberano) e se posicionando contrariamente à participação dos indivíduos por meio do "sufrágio universal" (voto); além das negativas às "manifestações políticas das massas populares”, estabelecendo assim, "desde o seu nascimento", um verdadeiro conflito com a democracia. Estas perspectivas foram ressaltadas no livro Indivíduo contra o Estado de Herbert Spencer (18201903), em que o autor

defende o sistema da concorrência como uma espécie de "seleção natural" dos mais
aptos, um darwinismo social. Spencer ataca duramente a democracia, a
intervenção estatal na economia e a criação de políticas sociais. Algumas das ideias
de Spencer seriam depois retomadas quase literalmente pelos autores neoliberais
contemporâneos (MORAES, 2001, p. 12, grifo nosso).

Baseado nos princípios de livre concorrência e ataque à democracia, surge a ideologia neoliberal, que inicialmente foi defendida pelo austríaco Ludwig Von Mises (1881-1973) e, posteriormente, por seu discípulo Friedrich Von Hayek (1899-1992), que teve maior repercussão em decorrência da publicação de sua obra, em 1944, O caminho da servidão, sendo considerado um documento de referência do movimento neoliberal. Neste livro Hayek afirmava a

necessidade de guardar intactos os princípios da "sociedade aberta". Daí vem a sua crítica do Estado-providência, tido como destruidor da liberdade dos cidadãos e da competição criadora, bases da prosperidade humana (MORAES, 2001, p. 13).

Observa-se, então, que o neoliberalismo se posiciona, assim como o liberalismo, contrariamente às intervenções do Estado, que impossibilitariam a liberdade natural dos indivíduos e, por consequência, o progresso. Quando utilizamos a palavra "progresso", esta se relaciona ao modo de produção/acumulação capitalista, possibilitando-nos a compreensão de que "as origens do neoliberalismo estão muito mais nas transformações do capitalismo do que no reino nebuloso das ideologias", visto que, no decorrer de sua história, o capitalismo enfrentou inúmeras crises em suas estruturas, obrigando-o a se adaptar às novas necessidades e demandas, instaurando, assim, um "novo regime" para "superar as crises e dificuldades encontradas" (VIANA, 2008, p.4).

Os neoliberais estabeleceram como inimigos diretos o Estado de bem-estar social e os sindicatos dos trabalhadores. O Estado de bem-estar social foi defendido por John Maynard Keynes em sua obra Teoria geral do emprego, do juro e da moeda, publicada em 1936, vindo a ser conhecida como doutrina Keynesiana, que tinha como princípios a convicção de que o 
Estado deveria manejar grandezas macroeconômicas sobre as quais era possível acumular conhecimento e controle prático. O poder público, desse modo, regularia as oscilações de emprego e investimento, moderando as crises econômicas sociais. O New Deal americano e o Estado de bem-estar europeu iriam testar (e aprovar durante bom tempo) a convivência do capitalismo com um forte setor público, negociações sindicais, políticas de renda e seguridade social, etc. Em suma, em pouco tempo, o Estado viu-se em condições e na obrigação de controlar o nível da atividade econômica, inclusive o emprego, através de instrumentos como a política monetária, a taxa de juros e os gastos públicos (MORAES, 2001, p. 14).

O neoliberalismo não era favorável a esse posicionamento do Estado, pois afirmava que suas ações interventivas e reguladoras na economia seriam a causa das crises do capital. Por outro lado, os defensores de Keynes acreditam que o Estado de bem-estar social era capaz de diminuir as desigualdades sociais geradas pelo mercado (MORAES, 2001). No que diz respeito aos sindicatos, estes eram tidos como ferramenta da classe trabalhadora, capaz de exercer uma sabotagem nas "bases de acumulação privada", por meio das "reivindicações salariais", que ocasionaram ao Estado um "crescimento parasitário"; ou seja, aumento com "despesas sociais e investimentos que não tinha perspectiva de retorno" (idem, p.13).

Falaremos, no próximo tópico, acerca das influências do neoliberalismo na América Latina, especialmente no Brasil, focalizando as discussões que dizem respeito às influencias na educação brasileira.

\section{Neoliberalismo: influência na América Latina e no Brasil}

Na América Latina, o inimigo a ser combatido era o Estado desenvolvimentista e nacionalista. Para isso, os neoliberais traçaram um plano estratégico que,

\footnotetext{
primeiro, desenha um diagnóstico apocalíptico. Em seguida, prega uma receita salvacionista: forte ação governamental contra os sindicatos e prioridade para uma política anti-inflacionária monetarista (doa a quem doer) - reformas orientadas para e pelo mercado, "libertando" o capital dos controles civilizadores que the foram impostos por duzentos anos de lutas populares (MORAES, 2001, p. 13-14, grifo nosso).
}

Nota-se que este cenário revela as intenções reformistas dos neoliberais, que foram direcionadas inicialmente aos países latino-americanos. De acordo com Filgueiras (2006, p.180), “o Brasil foi o último país da América Latina a implementar um projeto neoliberal”, esse fato foi, para o autor, derivado: "de um lado, à dificuldade de soldar os distintos interesses das diversas frações do capital, até então presentes no moribundo Modelo de Substituição de Importações e, de outro, à intensa atividade política desenvolvida pelas classes trabalhadoras na década de 1980". 
Ainda, segundo Boito Jr (2006), nesse processo de implementação do modelo neoliberal no Brasil, há o destaque para o fato de que um elemento geral e permanente da política neoliberal foi atender aos interesses do conjunto da burguesia e do imperialismo, evidenciando um Estado com políticas de desregulamentação do mercado de trabalho, de redução de salários e de redução ou supressão de gastos e direitos sociais, além de sustentar efetivamente a implementação de uma política de privatização, caracterizando, assim, o ingresso do país no modelo efetivamente neoliberal.

Contribuindo com essa discussão, Massino (2013, p. 150) afirma que as explicações sociológicas também variam bastante, com interpretações compondo suas explicações "a partir dos conflitos distributivos deflagrados com a implantação das reformas, ou, por outra via, mediante a análise dos valores e das opiniões predominantes entre as elites ou entre a população brasileira, durante a década de1990 do século XX".

Vale lembrar que esse movimento já estava ocorrendo em outros países da América Latina anteriormente, conforme destaca Moraes (2001, p.16) ao afirmar que as "primeiras grandes experiências do 'ajuste' neoliberal na América Latina” ocorreram em “1973 no Chile, e, posteriormente, na Argentina em 1976. Durante a década de 1980,

os programas neoliberais de ajuste econômico foram impostos a países latinoamericanos como condição para a renegociação de suas dívidas galopantes. Daí se passou à vigilância e ao efetivo gerenciamento das economias locais pelo Banco Mundial e pelo FMI: 1985, Bolívia; 1988, México, com Salinas de Gortari; 1989, novamente a Argentina, dessa vez com Menen; 1989, Venezuela, com Carlos Andrés Perez; 1990, Fujimori, no Peru. E, desde 1989, o Brasil, de Collor a Cardoso (MORAES, 2001, p. 16-17, grifo nosso).

Destacamos, no excerto supracitado, as palavras: condição, renegociação, dívidas, gerenciamento, Banco Mundial e FMI, a fim de evidenciar e explicar como se deu o processo de inserção das políticas neoliberais na economia dos países latino-americanos. Por meio dessas palavras, têm-se a compreensão de que a renegociação das gigantes dívidas, que esses países contraíram no decorrer dos anos, só seria possível por meio de uma condição imposta pelo Banco Mundial e o FMI (Fundo Monetário Internacional), no sentido de permitir que as políticas neoliberais adentrassem os governos impondo métodos de fiscalização e gerenciamento das economias locais, com o intuito de propor reformas "dos serviços públicos", direcionadas por "uma ideia reguladora: a ideia de privatizar" (MORAES, 2002, p. 20).

Contudo, as políticas reformistas, influenciadas pela corrente neoliberal, 
não visam apenas a acertar balanços e cortar custos - garantindo o sagrado superávit primário, imprescindível à remuneração dos juros da dívida (interna e externa). Trata-se de mudar a agenda do país. De modificar drasticamente os temas e valores compartilhados, de modo que se enquadrem às eventuais alternativas no terreno pejorativo do impensável; e de alterar em profundidade os espaços e processos em que se faz política, isto é, em que se fazem escolhas relevantes. Mesmo quando essas deliberações sejam "públicas" - já que não se pode lançá-las, infelizmente, às decisões (supostamente) descentralizadas do mercado -, que esse espaço seja cada vez mais parecido com o seu senhor, [...] o mercado (idem, p. 20, grifo nosso).

Neste sentido, verifica-se que a ação da corrente neoliberal age diretamente nos países em que se insere, causando alterações no modo de gerir as políticas, direcionando-as para o benefício do mercado. Resumidamente, as ideias neoliberais pregam a necessidade de

\begin{abstract}
privatizar empresas estatais e serviços públicos, por um lado; por outro, "desregulamentar", ou antes, criar novas regulamentações, um novo quadro legal que diminua a interferência dos poderes públicos sobre os empreendimentos privados. O Estado deveria transferir ao setor privado as atividades produtivas em que indevidamente se metera e deixar a cargo da disciplina do mercado as atividades regulatórias que em vão tentara estabelecer (MORAES, 2001, p. 18).
\end{abstract}

Quando o autor aponta que os neoliberais visam privatizar empresas estatais e órgãos públicos, isso inclui também a educação, a saúde, a previdência, entre outros direitos sociais conquistados, tidos nessa perspectiva como um "efeito perverso" gerado pelo Estado de bemestar social, que ao promover ações políticas protecionistas produz um “clientelismo", ou seja, indivíduos dependentes do Estado, gerando aumento nos gastos públicos e enfraquecendo as empresas privadas que poderiam atuar nesses setores de serviço (MORAES, 2001, p.18).

Para além da privatização dos serviços públicos e o enfraquecimento dos Estados nacionais, a ideologia neoliberal

acaba transferindo muitas dessas regulações (produção de normas, regras e leis) para uma esfera maior: as organizações multilaterais como o G-7, a OMC, o Banco Mundial, o FMI, dominadas pelos governos e banqueiros dos países capitalistas centrais (MORAES, 2001, p. 20).

Diante deste contexto, verifica-se que o neoliberalismo estabeleceu aproximações com os organismos multilaterais, bem como, suas ações foram realizadas por meio deles. Uma destas ações é a tentativa de tornar bens e serviços públicos em "mercado ou quase-mercado", é o caso da educação. Falaremos, no próximo tópico, de forma mais abrangente sobre os estudos já realizados no Brasil sobre educação e neoliberalismo (MORAES, 2001, p. 31).

No decorrer da década de 1970, na América Latina, parte dos países apresentavam governos ditatoriais, tais governos efetuaram empréstimos junto ao Banco Mundial (BM), 
para alavancar o desenvolvimento local de suas nações. Em contrapartida, esse fato representou endividamento desses países

[...] no final dos anos 70, como consequência de medidas do banco central norte americano, a taxa de juros aplicada à dívida triplica-se e torna esses países absolutamente inadimplentes. A renegociação da dívida é cada vez mais submetida a "programas de ajuste" com suas "condicionalidades": mudanças estruturais dirigidas e vigiadas pelo Banco Mundial e pelo FMI.

Paralelo ao contexto desse período havia um

amplo processo internacional de desregulamentação e liberalização dos fluxos comerciais e financeiros, impulsionado e imposto a partir dos governos Thatcher e Reagan. Alguns dão a esse novo cenário um nome elegante: globalização. Aos países subdesenvolvidos, caberia o destino da "integração competitiva" na nova divisão internacional do trabalho. Esses elementos descrevem a primeira tendência, a lógica dos mercados e da eficiência (MORAES, 2001, p.36, grifo nosso).

Observa-se que estes excertos retratam como se deu a inserção inicial dos princípios neoliberalistas nas economias dos países latino-americanos a partir da década de 1970, período que compreendeu a globalização e a necessidade de se estabelecer novos modelos de divisão do trabalho, para atender às demandas da lógica do mercado e da eficiência. Posteriormente, já na década de 1980, o Brasil viveu um período pós-ditadura militar que foi considerado pelos economistas como uma "década perdida", enquanto que para os cientistas sociais configurou-se num cenário histórico de "espaços conquistados", tendo em vista a aquisição de direitos sociais garantidos por meio da Constituição Federal de 1988 (MORAES, 2001, p.37).

Neste sentido, as políticas sociais se concentraram apenas em diminuir a pobreza gerada pelo mercado, adquirindo, assim, um plano de ação "focalizado", em que o acesso aos direitos sociais é seletivo, ou seja, direcionados para uma pequena parcela da população, ganhando, assim, um caráter compensatório das desigualdades geradas pelo sistema capitalista (MORAES, 2001).

Em 1996, entrou em vigor no Brasil a Lei de Diretrizes e Bases da Educação Nacional (LDB, 9394/96), que se configurou um documento norteador para a educação nacional, contendo várias orientações e disposições para alavancar a educação em um período de dez anos. Para cumprir essa meta, a LDB apresenta em seu texto, especificamente no "Título IX Das Disposições Transitórias", no Art. 87, a determinação de que "é instituída a Década da Educação, a iniciar-se um ano a partir da publicação dessa Lei”. Neste artigo a LDB determina, no parágrafo $1^{\circ}$, que 
A União, no prazo de um ano a partir da publicação desta Lei, encaminhará, ao Congresso Nacional, o Plano Nacional de Educação, com diretrizes e metas para os dez anos seguintes, em sintonia com a Declaração Mundial sobre Educação para Todos (BRASIL, 1996).

Percebemos, então, que uma das principais leis que regulamenta a educação brasileira contém em seu texto determinações reformistas que seguem a linha das diretrizes mundiais para a educação, sugeridas pelo BM e seus organismos na "Declaração Mundial de Educação para Todos". Para Jimenez e Mendes Segundo (2007, p. 125), o Brasil

vem, de fato, praticando a contenção dos gastos com a educação pública, priorizando, mesmo assim avaramente, o ensino fundamental, lançando o ensino médio e o superior à arena da privatização, além de fazer jorrar suas graças financeiras pelos cofres das empresas privadas de ensino superior, como vem sendo denunciado em plenas medidas.

O fato de priorizar a educação básica em detrimento da educação superior é uma tendência explicitada em grande parte dos documentos elaborados pelo BM e seus parceiros. Um exemplo claro é o documento Prioridades y estratégias para La educación, de autoria do $\mathrm{BM}$, em que infere a "educação básica como prioridade", enquanto que a educação profissional e de nível superior deve ser oferecida pela iniciativa privada (BANCO MUNDIAL, 1996, p. 11).

De acordo com este mesmo documento do BM, em relação ao Ensino Superior, este deve ser ofertado

\begin{abstract}
por meio da cobrança de direitos em toda a educação publica superior, combinada com empréstimos, financiamentos e outros planos, para que o estudante que não pode pagar os direitos com sua renda ou de seus pais possam adiar o pagamento até que eles tenham a sua própria renda (BANCO MUNDIAL, 1996, p. 116, tradução nossa).
\end{abstract}

Constata-se que, na visão do BM, o Ensino Superior deve ser oferecido por meio de "cobranças de direitos" que, trocando em miúdos, representa a privatização desta modalidade de ensino, ou mesmo, a sua oferta mediante a realização de empréstimos e financiamentos para o ingresso na educação superior. Cabe-nos ressaltar aqui, que esta característica representa o endividamento de muitos jovens e, ao mesmo tempo, a desresponsabilização do Estado frente à mercantilização da educação superior.

Após analisar as perspectivas neoliberais que influenciaram a formulação e a implementação de algumas políticas reformistas e focalizadas que permearam a educação brasileira, bem como, as fragilidades geradas por elas, o próximo tópico apresentará estudos 
educacionais publicados na base de dados online "Scielo", possibilitando a apresentação de um panorama acerca da produção do conhecimento em um período que compreende dez anos.

\section{Panorama dos estudos publicados focalizados em descritores educacionais}

Para traçarmos um panorama da produção acadêmica voltada à educação, foram selecionados estudos publicados na base eletrônica de dados "Scielo", por meio de buscas focalizadas nos seguintes descritores: a) trabalho docente; b) precarização; c) professor; d) políticas educacionais e) neoliberalismo. O critério para participação nesta pesquisa foi a presença destes descritores no título do trabalho ou no corpo do resumo, publicados entre os anos de 2007-2017. Utilizou-se como ferramenta de busca a delimitação dos artigos em português dos periódicos e revistas brasileiras, tendo como área temática as Ciências Humanas - educação e pesquisas educacionais.

Vejamos os resultados encontrados que compreendem os estudos publicados que se enquadraram nestes critérios:

Tabela 1 - Artigos publicados na base de dados Scielo entre 2007-2017

\begin{tabular}{|c|c|c|c|c|c|c|c|c|c|c|c|c|}
\hline \multicolumn{13}{|c|}{ Ano de publicação } \\
\hline Descritores & $\begin{array}{l}200 \\
7\end{array}$ & $\begin{array}{l}200 \\
8\end{array}$ & $\begin{array}{l}200 \\
9\end{array}$ & $\begin{array}{l}201 \\
0\end{array}$ & $\begin{array}{l}201 \\
1\end{array}$ & $\begin{array}{l}201 \\
2\end{array}$ & $\begin{array}{l}201 \\
3\end{array}$ & $\begin{array}{l}201 \\
4\end{array}$ & $\begin{array}{l}201 \\
5\end{array}$ & $\begin{array}{l}201 \\
6\end{array}$ & $\begin{array}{l}201 \\
7\end{array}$ & Total \\
\hline $\begin{array}{l}\text { Trabalho } \\
\text { Docente }\end{array}$ & 8 & 8 & 10 & 13 & 5 & 17 & 10 & 8 & 10 & 9 & 8 & 106 \\
\hline Precarização & 1 & - & 2 & - & - & 1 & - & - & 1 & 4 & 1 & 10 \\
\hline Professor & 8 & - & 11 & 13 & 11 & 23 & 20 & 16 & 15 & 16 & 24 & 157 \\
\hline $\begin{array}{l}\text { Políticas } \\
\text { Educacionais }\end{array}$ & - & - & - & 4 & 3 & 7 & 12 & 8 & 3 & 8 & 3 & 48 \\
\hline Neoliberalismo & 2 & 2 & 3 & 2 & 2 & 2 & 3 & 5 & 4 & 3 & 9 & 37 \\
\hline $\begin{array}{l}\text { Total de } \\
\text { Artigos }\end{array}$ & 19 & 10 & 23 & 32 & 21 & 50 & 42 & 37 & 33 & 40 & 45 & 358 \\
\hline
\end{tabular}

Fonte: A autora.

De acordo com os dados apresentados na Tabela 1, a produção acadêmica total de todos os descritores pesquisados foi de 358 trabalhos. O descritor "professor" foi o mais 
publicado na base de dados Scielo, aparecendo 157 vezes, enquanto que o descritor “precarização" apareceu em apenas 10 pesquisas entre os anos de 2007-2017. O ano de 2012 apresentou um total de 50 publicações envolvendo os 5 descritores, compreendendo o maior índice de publicação entre os anos pesquisados.

Nas buscas que compreenderam o descritor "neoliberalismo", este apareceu em apenas 37 estudos durante os 11 anos pesquisados, entretanto, em 2017, houve um pequeno aumento nas publicações, computando 9 estudos. Por meio da observação da tabela construída com os dados da Plataforma Scielo, constatou-se que as pesquisas educacionais que relacionam a perspectiva neoliberal com a educação, bem como, com as fragilidades educacionais ocasionadas por ela, carecem de publicações, visto que os princípios neoliberais estão atrelados historicamente à formulação e execução de políticas públicas reformistas focalizadas, que afetam o sistema educacional brasileiro.

Destaca-se, ainda, o fato de que os dados encontrados, acerca da precarização e do trabalho docente estão atrelados às mudanças provocadas pelas políticas neoliberais, vão ao encontro das afirmativas de Hypolito et al (2009) ao afirmarem que as ações são resultantes da combinação da centralização e descentralização no setor educacional, tais como os mecanismos de regulação de avaliação educacional, projetos de reformas e constantes mudanças na organização de programas de formação e atualização docente.

De acordo com Santos (2002), essas mudanças e formas de se tratar as políticas educacionais, a partir do neoliberalismo, estão atreladas à própria reestruturação da economia mundial na perspectiva de hegemonia da sociedade de mercado, tendo como vistas a continuidade da organização de mercados comuns, que tem sido uma das estratégias implementadas pelas políticas neoliberais.

A observância desses achados no estudo denotam indicadores de como o setor educacional tem sido influenciado pelas ações e políticas de gerenciamento neoliberais, com foco na manutenção e efetivação de um sistema, no qual a qualidade da educação está secundarizada ao prisma da quantificação dos resultados apresentados.

\section{Considerações finais}

Este estudo se propôs a fazer um percurso histórico das correntes liberais e neoliberais, por meio da análise sistemática de bases teóricas, trazendo à cena seus princípios e ações direcionados à sociedade, especialmente no que diz respeito às políticas educacionais brasileiras, que foram influenciadas sobremaneira pelas dinâmicas econômicas e 
mercadológicas e regem as ações e intenções políticos-governamentais, baseadas no neoliberalismo, bem como, as influências no campo educacional brasileiro.

Foram apresentadas as perspectivas neoliberalistas de diminuir as interferências do Estado na economia e, em contrapartida, a instauração de políticas reformistas visando à modificação do Estado de bem-estar social (garantia de direitos sociais) para o chamado Estado-mínimo, no qual as políticas, bem como, as políticas públicas educacionais, são focalizadas apenas em setores mais críticos, no sentido de combater a pobreza extrema. $\mathrm{Na}$ educação, o foco se dá na educação básica, enquanto que o Ensino Superior é precarizado, estimulando a privatização deste nível de ensino.

Neste sentido, verificou-se, por meio da busca de estudos na base de dados "Scielo" entre os anos de 2007-2017, com a utilização dos descritores: "trabalho docente", “precarização", "professor”, "políticas educacionais" e "neoliberalismo”, um panorama demonstrativo na produção acadêmica destes descritores nesse período. Foram encontrados 358 estudos no total, onde o descritor "professor" obteve a maior quantidade de pesquisas publicadas: 157, enquanto que o descritor "precarização" apresentou o menor número: apenas 10. Por fim, observou-se que o descritor "neoliberalismo" possui poucas publicações, totalizando 37 estudos. Portanto, constatou-se que as pesquisas educacionais que relacionam a perspectiva neoliberal com a educação, bem como, com as fragilidades educacionais ocasionadas por ela, carecem de mais publicações. Visto que os princípios neoliberais estão atrelados historicamente à formulação e execução de políticas públicas reformistas, que por sua vez, demonstraram afetar o sistema educacional brasileiro, focalizando seus esforços na educação básica em detrimento ao Ensino Superior, sugerindo a sua privatização, atendendo, assim, às demandas do mercado.

Contudo, para que a realidade educacional brasileira seja modificada, assim como as leis que a regulamentam de forma restritiva, faz-se necessário que a população seja conscientizada a respeito das influências imprimidas pelo neoliberalismo, por meio do BM e seus organismos internacionais, com o intuito de desmistificar as parcerias entre o Estado e esses órgãos internacionais e, ao mesmo tempo, possibilitar uma ruptura com a lógica capitalista, para que possamos vislumbrar uma educação significativamente diferente desta que está posta na atualidade. 


\section{Referências}

ANTUNES, Ricardo. “A era da informatização e a época da informalização: riqueza e miséria do trabalho no Brasil". In: Ricardo Antunes (org). Riqueza e Miséria do Trabalho no Brasil. São Paulo, SP. Boitempo, 2006.

BANCO MUNDIAL. Prioridade y estrategias para la educación.1996.

BRASIL. Lei de Diretrizes e Bases da Educação Nacional. 1996.

BOITO JR., Armando. As relações de classe na nova fase do neoliberalismo no Brasil. In: Sujetos sociales y nuevas formas de protesta en la historia reciente de América Latina. CLACSO, Consejo Latinoamericano de Ciencias Sociales. Buenos Aires, 2006.

BOURDIEU, Pierre. Contrafogos: táticas para enfrentar a invasão neoliberal. Rio de Janeiro: Zahar, 1998.

CORDEIRO, Alexander Magno ; OLIVEIRA, Glória Maria de; RENTERÍA, Juan Miguel; GUIMARÃES, Carlos Alberto. Revisão Sistemática: Uma Revisão Narrativa. Rev. Col. Bras. Cir. Vol. 34 - Nº, Nov. / Dez. 2007.

FILGUEIRAS, Luiz. O neoliberalismo no Brasil: estrutura, dinâmica e ajuste do modelo econômico. In: Neoliberalismo y sectores dominantes. Tendencias globales y experiencias nacionales. Basualdo, Eduardo M.; Arceo, Enrique. CLACSO, Consejo Latinoamericano de Ciencias Sociales, Buenos Aires. Agosto 2006. ISBN: 987-1183-56-9.

HYPOLITO. Alvaro Moreira; VIEIRA, Jarbas Santos; PIZZI, Laura Cristina Vieira. Reestruturação curricular e autointensificação do trabalho docente. Currículo sem Fronteiras, v.9, n.2, pp.100-112, Jul/Dez 2009.

JIMENEZ, Susana Vasconcelos; MENDES SEGUNDO, Maria das Dores Mendes. Erradicar a pobreza e reproduzir o capital: Notas críticas sobre as diretrizes para a educação do novo milênio. Pelotas, Editora da UFPEL, Ano 16, N. 28, Jan-Jun 2007, p. 119 - 138.

MASSINO, Lucas. Como Se Explica O Neoliberalismo No Brasil? Uma Análise Crítica Dos Artigos Publicados Na Revista Dados. Revista de Sociologia e Política. v. 21, No 47: 133-153 Set. 2013.

MENDONÇA, Camila Tecla Mortean. O estado do Conhecimento na educação superior a distancia e a intervenção dos organismos internacionais nas políticas públicas (2001-2014). 137 f. Dissertação (Mestrado Educação) - Universidade Estadual de Maringá. Orientadora: Profa. Dra. Maria Luisa Furlan Costa. Maringá, 2016.

MORAES, R.C. Liberalismo e Neoliberalismo - uma introdução comparativa. Campinas, São Paulo: IFCH/UNICAMP: Primeira Versão, nº 73, novembro/1997.

MORAES, R.C. Neoliberalismo: de onde vem, para onde vai? São Paulo: SENAC, 2001. 
MORAES, R.C. Reformas neoliberais e políticas públicas: hegemonia ideológica e redefinição das relações Estado-sociedade. Educ. Soc., Campinas, vol. 23, n. 80, setembro/2002, p. 13-24.

OLIVEIRA, Dalila Andrade. A Reestruturação do trabalho docente: precarização e flexibilização. Educação e Sociedade, V. 25, N 89, 2004.

ROMANOWSKI, Joana Paulin; ENS, Romilda Teodora. As Pesquisas Denominadas Do Tipo "Estado Da Arte”" Em Educação. Diálogo Educ., Curitiba, v. 6, n.19, p.37-50, set./dez. 2006.

SANTOS, Boaventura de S. A Globalização e as Ciências Sociais. São Paulo : Cortez Editora, 2002.

SMITH, Adam. A riqueza das nações - investigação sobre sua natureza e causas. São Paulo: Abril Cultural, v. II, 1983.

VIANA, Nildo. Breve história do neoliberalismo. Revista Enfrentamento, n. 05, jul./dez. 2008. 